\title{
Nasal Vestibular Stenosis as a Nasogastric Tube Related Complication
}

\author{
${ }^{1}$ AK Kairo, ${ }^{2} \mathrm{R}$ Madan, ${ }^{3} \mathrm{CA}$ Singh, ${ }^{4} \mathrm{~S}$ Singh
}

\begin{abstract}
The nasogastric tube is an efficient way for giving enternal nutrition in patients who are not able to take oral feeds. It is a simple procedure that can be done by any caregiver with minimal training even in a remote area. Complications are rare, there are few reported cases of esophageal perforation, inadvertent tracheobronchial or intracranial intubation, pneumothorax, and bronchopleural fistula associated with the passing of this tube. Prolonged use of nasogastric tube causes continuous pressure over the soft triangle of the nose leading to pressure necrosis and stenosis of nasal vestibule.
\end{abstract}

Keywords: Nasogastric tube, Complications, Vestibular stenosis.

How to cite this article: Kairo AK, Madan R, Singh CA, Singh S. Nasal Vestibular Stenosis as a Nasogastric Tube Related Complication. Clin R hinol An Int J 2014;7(1):26-27.

\section{Source of support $\mathrm{Nil}$}

\section{Conflict of interest None}

\section{INTRODUCTION}

The nasogastric tube is an efficient way for giving enteral nutrition in patients who are not able to take oral feeds. It is a simple procedure that can be done by any caregiver with minimal training even in a remote area. The cost of the whole procedure is negligible as compared to other modes of enteral nutrition like percutaneous endoscopic gastrostomy (PEG). ${ }^{1}$ Though complications are rare, there are few reported cases of esophageal perforation, inadvertent tracheobronchial or intracranial intubation, pneumothorax, and bronchopleural fistula associated with the passing of this tube. ${ }^{2}$

Prolonged use of nasogastric tube causes continuous pressure over the soft triangle of the nose leading to pressure necrosis. ${ }^{3}$ Soft triangle (caudal lobular notch) is a small indentation or notch lies just caudal to the intermediate crus of lower margin of lower lateral cartilage. ${ }^{4}$ Soft triangle is

\footnotetext{
1,2,4 Senior Resident, ${ }^{3}$ Assistant P rofessor

${ }^{1,3,4}$ Department of ENT, Head and Neck Surgery, All India Institute of Medical Sciences, New Delhi, India

${ }^{2}$ Department Radiotherapy, All India Institute of Medical Sciences, New Delhi, India
}

Corresponding Author: Amit Singh Chirom, Assistant Professor Department of ENT, Head and Neck Surgery, All India Institute of Medical Sciences, New Delhi, India, e-mail: amitchirom@ gmail.com crucial in external nasal appearance. It is considered the most challenging to reconstruct soft triangle during rhinoplasty so it not touched during surgery and considered sacred. ${ }^{5}$

\section{CASE REPORT}

This case is of a male child who stayed in the Intensive care unit after corrective surgery for congenital heart disease. during the ICU stay, patient was on enteral feeds via nasogastric tube, which was subsequently removed when the patient was able to take oral feed without any sign of aspiration. On removal of NG tube, there was ulceration seen at the area of the soft triangle. This was managed conservatively with topical medication. Three months following discharge from the hospital, patient was presented to us for nasal deformity. On evaluation, it was found to be nasal vestibular stenosis with scarring of ala (Fig. 1). Patient was having only cosmetic problem without any functional morbidity at present.

\section{DISCUSSION}

Complications like nasal bleeding, mucosal laceration, inadvertent tracheobronchial or intracranial intubation, pneumothorax, and bronchopleural fistula are occasionally observed following prolonged nasogastric tube insertion. $\mathrm{N}$ asal ala pressure sores are rarely reported. ${ }^{3}$

Pressure sores are like iceberg, the visible part being the tip of iceberg as majority of the damage is underneath the ulcer. The damage is in a conical form where only the tip is visible outside called 'cone of necrosis' ${ }^{6}$

Pressure sores are complex wounds and its formation is a result of multiple factors which includes pressure, time, infection, moisture and poor nutrition. ${ }^{7}$ In canine model, Kosiak et al demonstrated the inverse parabolic relationship between time and pressure in pressure sore formation. ${ }^{8}$

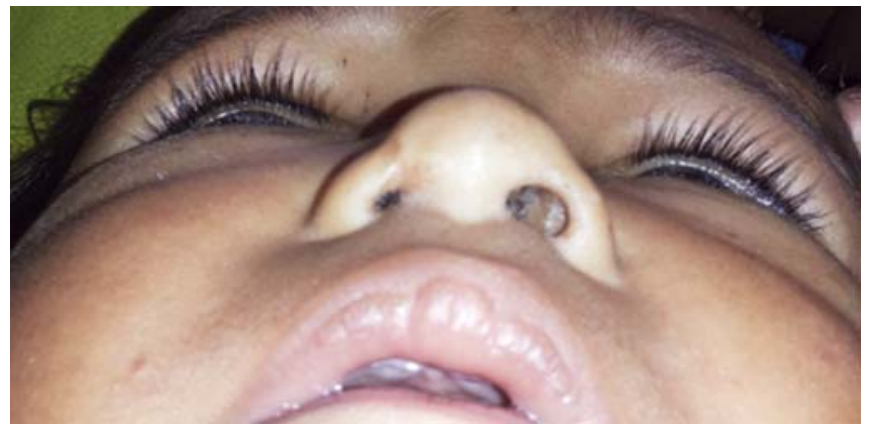

Fig. 1: Clinical photograph showing the nasal vestibular stenosis on the right side 
Tight fixing of nasogastric tube to the nose causes pressure to the soft triangle or the ala. If ignored, it can lead to pressure sores of these areas. In very rare instance, it can further progress to involve the al ar cartilage causing perichondritis. Therefore, when healed, it causes scarring of the soft triangle and rarely scarring of the ala and vestibular stenosis.

On reviewing the PubM ed database regarding nasogastric tube complications, we were not able to find such a similar complication in any of the articles cited.

\section{CONCLUSION}

Improper fixation of nasogastric tube may lead to alar deformity and vestibular stenosis. It is important to know these complications as early intervention can prevent such conditions.

\section{REFERENCES}

1. Corry J, Poon W, M CPhee N, M ilner AD, Cruickshank D, Porceddu SV, Rischin D, Peters LJ. Randomized study of percutaneous endoscopic gastrostomy versus nasogastric tubes for enteral feeding in head and neck cancer patients treated with (chemo) radiation. J M ed Imaging Radiat Oncol 20080 ct; 52(5):503-510.

2. Pillai JB, et al. Interactive cardiovascular and thoracic surgery 2005;4:429-433.

3. Seyedhejazi M , Hamidi M, Sheikhzadeh D, Sharabiani B A . Nasogastric tube placement errors and complications in intensive care unit: a case report. J Cardiovasc Thoracic Res 2011;3(4):133-134.

4. Huizing EH. Incorrect terminology in nasal anatomy and surgery, suggestions for improvement. R hinology 2003 Sep;41(3):129133.

5. Constantine FC, Lee M R, Sinno S, Thornton JF. Reconstruction of the nasal soft triangle subunit. Plast R econstr Surg 2013 M ay; 131(5):1045-1050.

6. Daniel RK, Priest DL, W heatley DC. Etiologic factors in pressure sores: an experimental model. A rch Phys M ed Rehabil 1981;62: 492-498.

7. Bass M J, Phillips L G. Pressure Sores; Curr Probl Surg 2007;44: 101-143.

8. Kosiak M, Kubicek WG, OIson M, Danz JN, Kottke FJ. Evaluation of pressure as a factor in the production of ischial ulcers. A rch Phys M ed Rehabil 1958;39:623-629. 